\title{
Ultrasonically Driven Silicon Atomizer and Pump
}

\author{
Amit Lal and Richard M. White \\ University of Califormia at Berkeley \\ Berkeley Sensor \& Actuator Center, Dept. of Electrical Engineering and Computer Sciences \\ 497 Cory Hall, Berkeley, California 94720-1770 USA
}

\begin{abstract}
High amplitude ultrasound, generated by a micromachined silicon resonant transducer, was used to atomize and pump liquids. The needle-shaped device made by bonding two silicon horns, is driven by lead zirconate titanate (PLT) piezoelectric plates. Water was atomized continuously at feed rates of $2.4 \mathrm{ml} / \mathrm{min}$ into a mist with mean drop size of $25 \mu \mathrm{m}$ at a $72 \mathrm{kHz}$ resonance frequency. An isopropanol mist was ignited to produce a spray combustion flame. When the vibrating tip is immersed in fluids, streaming forces cause the fluid to be pumped at rates of $10 \mathrm{ml} / \mathrm{min}$ and generate pressure as high as $0.75 \mathrm{psi}(5200 \mathrm{~Pa}$.)
\end{abstract}

\section{INTRODUCTION}

In this paper, we present further resulw on using a micromachined silicon ultrasonic resonant transducer which can generate high amplitude ultrasound (ultrasonic tip velocities as high as $23 \mathrm{~m} /$ $s=51 \mathrm{miles} /$ hour $=83 \mathrm{~km} /$ hour). Earlier [1,2] we used this silicon transducer to perform ultrasonic surgery on a human cataractous eye lens. While performing surgery, we noticed pumping and atomizing surrounding the tissue. A literature survey revealed that high strength titanium-alloy based ultrasonic transducers have been used before to pump and atomize liquids[13,14]. In particular, fuel atomization has been of practical significance for fuel combustion systems $[12,13]$.

Silicon based micro-fluidic systems are predicted to have applications in chemistry, biology and medicine. Examples include drug delivery, analysis and processing. Many of these structures consist of silicon wafer sandwiches, where fluids have to be delivered and

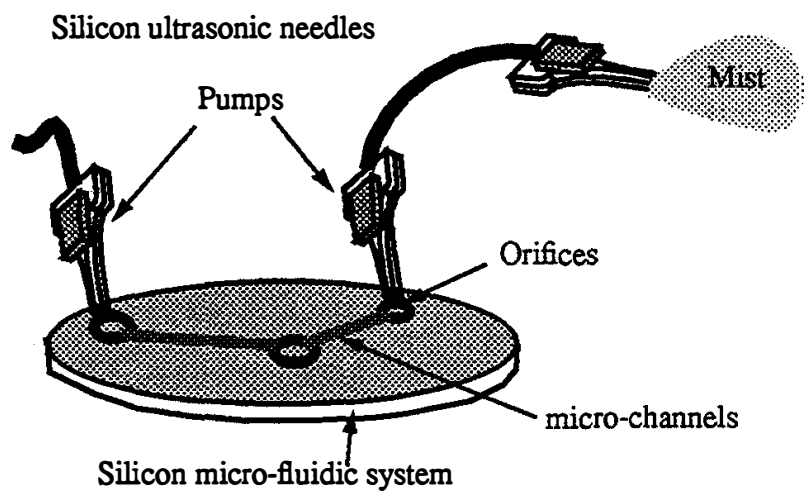

Figure 1. The silicon ultrasonic needle used both as a pump and an atomizer.



Figure 2. Conventional metal transducer and the silicon transducer

removed from micrometer size orifices. The pump presented in this paper can be made small enough to remove, deliver and atomize fluids from micro-fluidic systems (Figure 1.)

A conventional metal-based resonance transducer (Figure 2, top) is assembled by sandwiching PZT plates between a high strength titanium alloy horn amplifying section and a back reflecting mass. The PZT plates drive the structure in its longitudinal resonance mode. The resonators are designed such that some multiple number (usually 1-3) of half-wavelengths of acoustic wave fit along the length of the transducer. The horn focuses the ultrasonic energy to amplify the longitudinal motion of the tip. The PZT plates are placed at the displacement node of the resonator.

The silicon resonator tool (Figure 2, bottom) consists of two bonded silicon horn shaped plates. A channel is formed by Vgrooves on each plate. A PZT plate is bonded at the nodal point of the structure on one or both sides of the device. The $d_{31}$ coefficient 
Table 1. Ultrasonic properties of selected ultrasonic materials [5,6,7,15]

\begin{tabular}{|c|c|c|c|c|c|c|}
\hline Property & $\mathbf{Y}$ & Strength & Density & $S_{m} c$ & $\begin{array}{l}\text { Acoustic } \\
\text { Loss }\end{array}$ & $\begin{array}{c}\text { Acoustic } \\
\text { Impedance }\end{array}$ \\
\hline Material & $(\mathrm{GPa})$ & $(\mathrm{GPa})$ & $\left(\mathrm{Kg} / \mathrm{m}^{3}\right)$ & $(\mathrm{m} / \mathrm{s})$ & $1 / \mathrm{Q}$ & $\mathrm{Kg} / \mathrm{m}^{4} / \mathrm{s}$ \\
\hline Silicon & 190 & $6]_{15}$ & 2300 & 335 & $10^{5}$ & 661 \\
\hline Diamond & 1035 & 53 & 3500 & 881 & $\sim 10^{-5}$ & 1903 \\
\hline $\mathrm{Si}_{3} \mathrm{~N}_{4}$ & 385 & 14 & 3100 & 405 & $\sim 10^{-5}$ & 1092 \\
\hline $\mathrm{SiO}_{2}$ & 73 & 8.4 & 2500 & 622 & $\sim 10^{-5}$ & 427 \\
\hline $\mathrm{SiC}$ & 700 & 21 & 3200 & 444 & $\sim 10^{-5}$ & 1496 \\
\hline Titanum alloy $(C-120-A Y)$ & 110 & 0.9 & 4430 & 41 & $3 \times 10^{4}$ & 698 \\
\hline Carbon steel & 200 & 2.1 & 7900 & 53 & $\sim 10^{-4}$ & 1256 \\
\hline PZT 4 & 85 & 0.024 & 7600 & .93 & $\sim 2.5 \times 10^{-3}$ & 803 \\
\hline PZT 5 & 67.5 & 0.0276 & 7700 & 1.21 & $\sim 1.54 * 10^{-2}$ & 720 \\
\hline
\end{tabular}

causes the PZT to stretch and contract in the longitudinal direction when the applied electric field is in the thickness direction.

Silicon transducers have several significant over their metal counterparts: The tip displacements can be higher, and the losses and costs can be lower. The maximum tip velocity or displacement in an ultrasonic resonator is proportional to $S_{m} c$ [4]. Here $S_{m}$ is the fracture strain and $c$ is the speed of sound in the resonator material. $\mathrm{S}_{\mathrm{m}} \mathrm{c}$ for silicon is times higher than titanium alloy (Table 1, highlighted sections). Silicon can be driven eight time higher in amplitude than titanium alloys before failure. Since effects like pumping and atomization are due to high acoustic intensity, which is proportional to the square of the ultrasonic amplitude, silicon transducers can have 64 times higher pumping/atomization rates.

A problem experienced with the conventional metal transducers is heating at high ultrasonic amplitudes. Since silicon's dislocation density is very low ( 1 dislocation/cm3), its internal $Q$ is an order of magnitude higher than metal alloys. Hence, a silicon transducer will generate much less heat and have a higher device quality factor.

The conventional metal transducers are also costly $(>\$ 3000)$ because each is machined serially using expensive hard-alloy machining techniques. Micromachined silicon transducer can be inexpensively batch-fabricated to tighter tolerances. Furthermore, any strength reducing surface flaws can be eliminated by oxidation to recover high fracture strength of $7 \mathrm{GPa}$ [15]. Low cost, due to batch processing, will allow parallel operation of several silicon transducers for a fault tolerant system. Integrating stress, flow, and

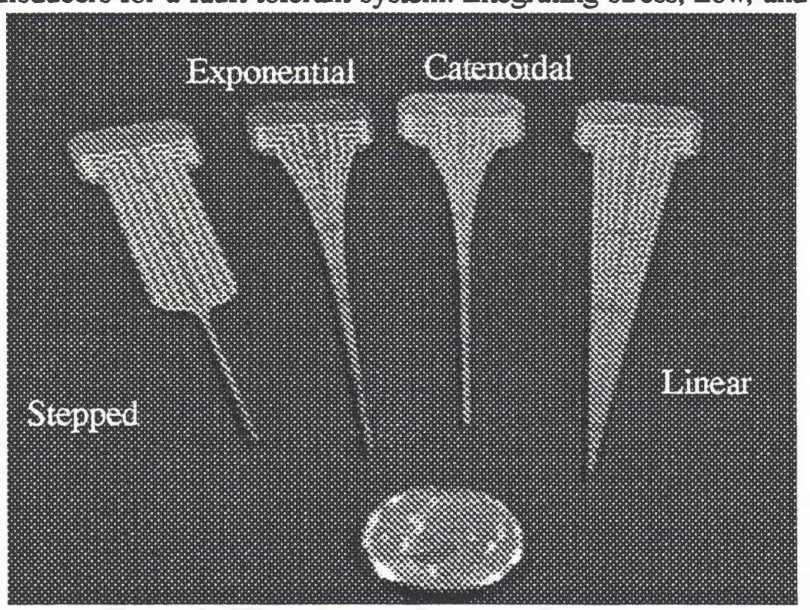

Figure 3. Silicon horns of various shapes (with a 10 cent coin) temperature sensors in the silicon device will permit operation with closed-loop control.

\section{FABRICATION}

The fabrication of the silicon transducer starts with a silicon nitride $(0.3 \mu \mathrm{m}$ thick) coated four-inch silicon wafer $(<100>$ orientation, $0.55 \mathrm{~mm}$ thick). Using photolithography and front-back alignment, the V-groove and the horn shapes are defined in a spunon photoresist. A standard nitride plasma etch was used to remove nitride from exposed areas. $\mathrm{KOH}$ anisotropic etch is used to etch silicon from front and back simultaneously, until the horn structures are suspended in the wafer by the thin silicon nitride membrane alone. The silicon horns (Figure 3) are broken free by a gentle push as the membranes are quite weak. After piranha and HF oxide removal, these horns are thermally oxidized $(0.5 \mu \mathrm{m}$ oxide) to passivate the silicon surface. Then a $1 \mu \mathrm{m}$ thick LPCVD deposited low-stress nitride is deposited conformably on all the horn surfaces to increase impact resistance of the final needle structure. Figure 5 shows the different shapes of horns fabricated.

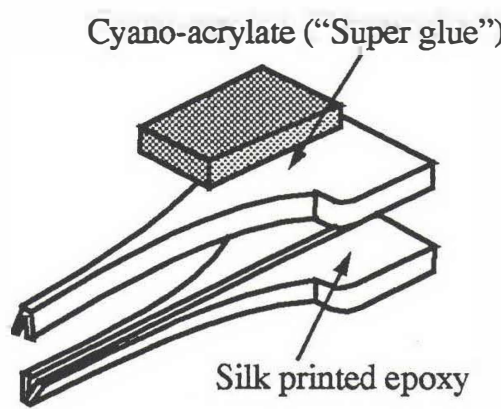

To form the structure (Figure 4), a thin layer of epoxy is screen printed on a set of horns. They are then aligned together on top of each other by using a piano wire inserted in the conduit formed by the two Vgrooves. The structure is then heat treated at $70^{\circ} \mathrm{C}$ for 1 hour for best epoxy strength. A Figure 4. Assembly of the silicon ultrasonic device

brass grommet is also epoxy glued at the shank side of the needle structure for the tubing connection. In the future, the two silicon horns will be joined with stronger bonding techniques like fusion, anodic or silicon-gold eutectic bonding. The ultimate strength of the bond will also determine the ultimate peak displacement amplitudes achievable with the silicon resonator.

PZT-4 plate ( $1 \mathrm{~mm}$ thick) is bonded at the nodal point of the ultrasonic resonator. Both super-glue (cyano-acrylate) and epoxy were tried. The former permitted obtaining a thinner bond and bet- 


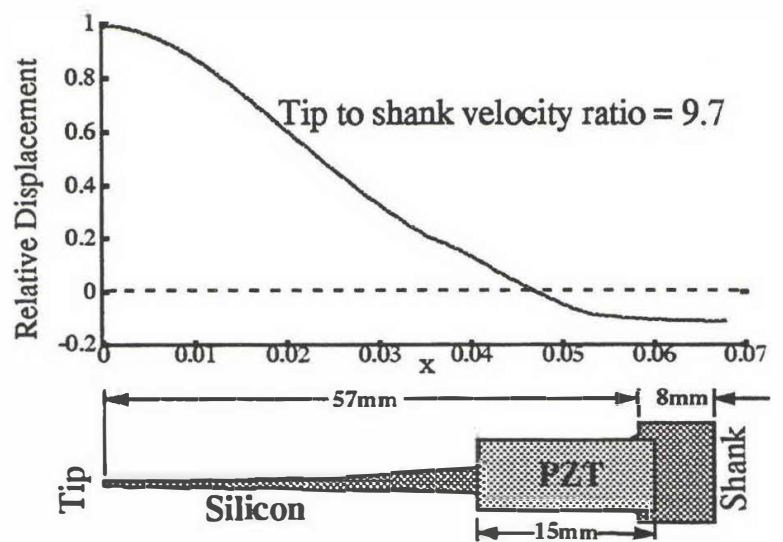

Figure 5. Numerically computed relative longitudinal displacement along the length of the silicon device.

ter acoustic coupling. After bonding, lead wires are soldered to the two faces of the PZT plate.

\section{DEVICE MODEL}

The usual balance between elastic and inertial forces on each infinitesimal section of the structure was used to model the steady state resonance of the silicon resonator. Because the thickness and width are much less than the length of the transducer, a onedimensional longitudinal wave propagation model can be used. Webster's hom equation [2] was solved numerically in the horn section as the cross-sectional areas varies along the length. Stressfree boundary conditions were applied to the PZT/silicon composite horn. The elastic effects of the "super glue" and the epoxy were not included in the model because of their negligible thicknesses compared to those of the silicon and PZT. An amplitude enhancement factor of 10 was measured under an optical microscope. This is in good agreement with the ratio of 9.6 obtained from the numerically computed displacement profile shown in Figure 5.

\section{MEASURED RESPONSE}

Figure 6 shows the electrical impedance measured using a HP 4195 impedance analyzer. The plot reveals a predicted transverse mode at $55 \mathrm{kHz}$ and the desired $\lambda / 2$ mode at $72 \mathrm{kHz}$. The full wavelength resonance is $95 \mathrm{kHz}$, followed by the first PZT halfwavelength resonance at $123 \mathrm{kHz}$. The impedance of the device

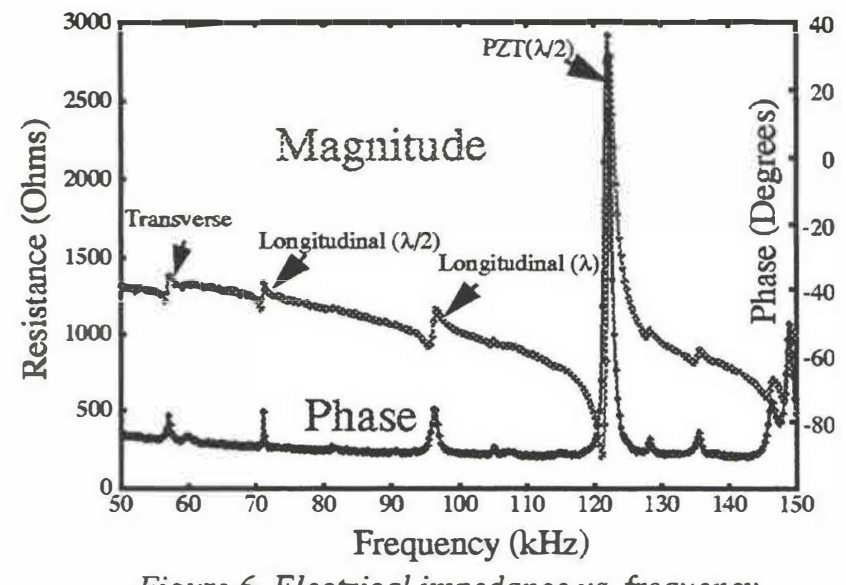

Figure 6. Electrical impedance vs. frequency

vs. frequency can be used to ascertain the quality factors, coupling coefficients, and the electrical model parameters for the device at a particular resonance [1]. The smaller in phase at resonance for the X/2 mode as compared to PZT mode indicates that coupling between the silicon and the PZT can be further improved by better bonding methods.

The maximum longitudinal displacement measured in air, when the transducer held at the nodal point by a X-acto blade holder was $100 \mu \mathrm{m}$ at a $200 \mathrm{Vpp}$ drive at $72 \mathrm{kHz}$ (The amplitude achieved was limited by the obtainable amplifier output.). This vibration amplitude implies a tip velocity of $23 \mathrm{~m} / \mathrm{s}$. In the future, we want to drive silicon to near its theoretical $S_{\mathrm{m}} \mathrm{c}$ velocity of $335 \mathrm{~m} / \mathrm{s}$ by using better coupling and multiple hom amplifying sections.

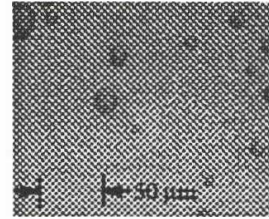

Figure 7. Droplets observed optically

\section{ATOMIZATION}

The high longitudinal vibration amplitude was used to atomize and pump fluids through the channel of the device. A fluid mist cone, one to five inches in length and one inch in diameter, was generated by the silicon atomizer. This ultrasonic atomization occurs in a two-stage process.

First, capillary waves form which are ejected once their amplitude becomes high enough [8]. Figure 7 shows droplets collected from the atomized mist on a hydrophobic plastic plate. Drop sizes were measured by measuring the drop size optically and multiplying by 0.70 [16]. The drop sizes measured were $20-35 \mu \mathrm{m}$. This range agrees with a mean diameter of $25 \mu \mathrm{m}$ obtained from an semiempirical expression [17].

$$
D=0.34\left(8 \pi \frac{T}{\rho f^{2}}\right)^{\frac{1}{3}} \begin{aligned}
& \text { Here } T \text { is the fluid surface tension, } \rho \text { is the } \\
& \text { fluid density and } \mathrm{f} \text { is the acoustical fre- } \\
& \text { quency. }
\end{aligned}
$$

\section{APPLICATION TO FUEL INJECTION}

Figure 8b. Flamethrower.

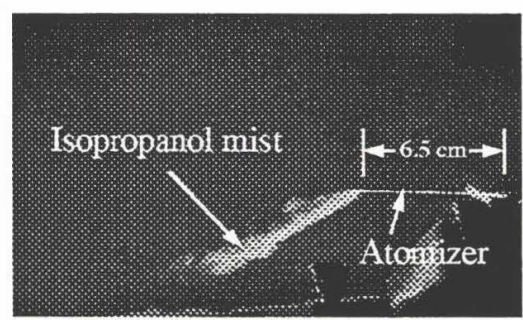

Figure 8a. Alcohol atomization

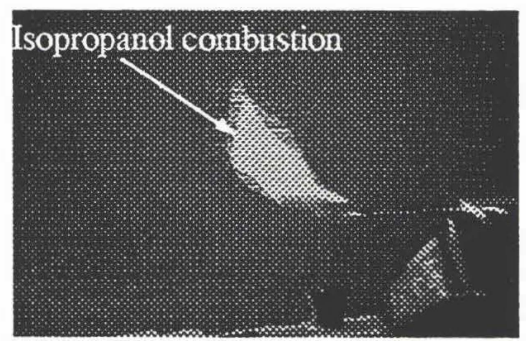

The rate at which fuel burns can be greatly enhanced by combusting the fuel in drop size from 30-60 $\mu \mathrm{m}$ [8] due to optimal mixing of air and fuel possible. Furthermore, more complete combustion and hence higher fuel burning efficiencies are possible. Most conventional fuel spray atomizers accelerate the fuel into turbulence, forcing it to break into drops. This requires high power pumps and moving equipment. Ultrasonic atomization eliminates needs for these pumps and inherently produces a low-velocity mist [11] that results in less wear. In order to investigate ultrasonic fuel combustion, we atomized isopropanol into a mist with the silicon device (Figure 8a.) Then we ignited the mist to measure the rate of combustion (Figure 8b.) 


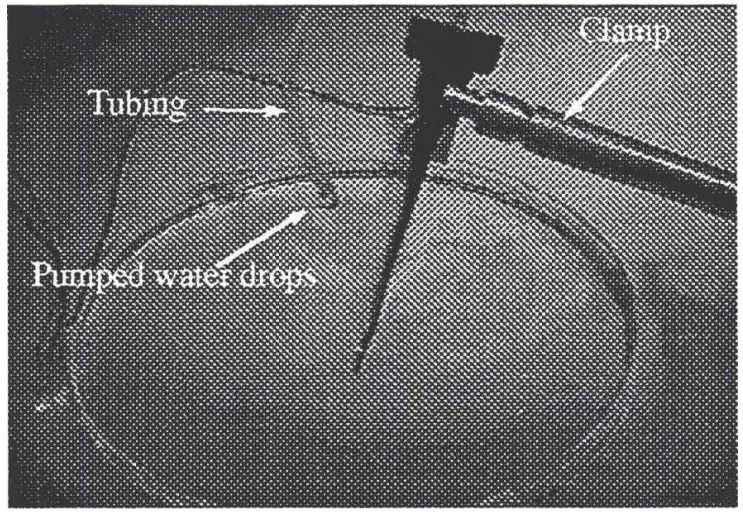

Figure 9. Evidence of pumping water against gravity

Continuous combustion at fuel feed rates of $2.4 \mathrm{ml} / \mathrm{min}$ was observed. The evidence of complete combustion was the absence of alcohol droplets leaving the flame.

\section{PUMPING}

The driven silicon device pumped water (Figure 9) when it was inserted in a petri-dish containing the water. Pumping is caused by forces generated by vortices induced by acoustic streaming (Figure 10.) The outward vortices are formed due to shear coupling at the outside walls of the device. The direction of these vortices is determined by the gradient of the motion along the horns and the stressfree boundary condition on the liquid surface. The outward flowing vortices induce a flow into the orifice. Zero-flow pump pressures as high as 0.75 psi was measured. Flow rate for a pressure differential of five inches of water was $10 \mathrm{~m} / \mathrm{min}$.

Using acoustic streaming theory, Jackson $[9,10]$ calculated the size and shape of streaming vortices generated by a solid bar vibrating longitudinally in a liquid. It was shown that the vortex sizes scale with the dimensions of the vibrating bar unless the dimensions approach that of the shear viscous layer. Below this dimension, streaming inside the shear viscous layer becomes important. This length is $\sqrt{\frac{2 v}{\omega}}$

Here $v$ is the kunematic viscosity of the fluid and $\omega$ is the radial frequency of operation. This layer is 2 $\mu \mathrm{m}$ thick for water at 72 $\mathrm{kHz}$.Hence, this pumping mechanism will work for needle orifice diameters two or three times this length. Using micromechanical techniques, it is possible to make a silicon pump whose outer diameter is $10 \mu \mathrm{m}$.

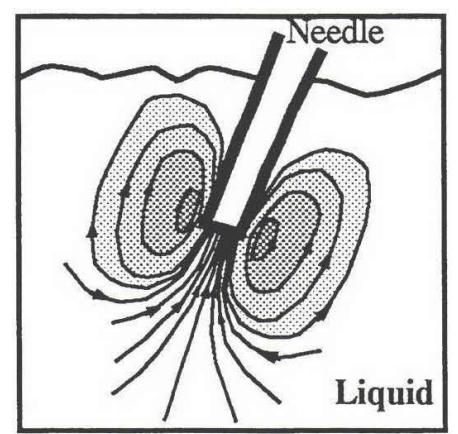

Figure 10. Vortex flow pattern at vibrating tip.

\section{CONCLUSIONS}

Silicon's material properties make it superior to titanium alloys as an ultrasonic transducer material. It's high ultimate particle velocity, $\mathrm{S}_{\mathrm{m}} \mathrm{c}$, and low acoustic loss make it ideal for high-amplitude ultrasonic applications. Silicon devices made by micromachining techniques, creates a new regime of high amplitude miniature ultrasound actuators. Batch fabrication, tight tolerances, and integration of sensors will increase the utility of the ultrasonic device.
We have used the silicon ultrasonic resonator to atomize and pump liquids such as water and isopropanol. The atomization at 72 $\mathrm{kHz}$ produced drop sizes varying from $25-35$ um with fluid rates as high as $2.5 \mathrm{ml} / \mathrm{min}$. We atomized isopropanol and ignited the mist to produce a sustained butane-torch like flame. This device could be used as a fuel injector in a small aircraft combustion engine. Arrays of these devices could be used to produce higher feed rates and fault-tolerant systems. The same device has been used to pump fluids via acoustic streaming. Zero-flow pump pressure of 0.75 psi was measured. Flow of $10 \mathrm{ml} / \mathrm{min}$ was obtained at a pressure differential of 5 inches of water.

In the future, we will integrate stress, displacement, temperature and flow sensors to actively control the rate of pumping and atomization. Better electrical-to-mechanical energy transduction is expected from better bonding of PZT to silicon homs, and PZT bonded on both top and bottom of device. Our goal is to develop a technology to remove, deliver and atomize fluids from micro-fluidic systems.

\section{REFERENCES}

[1] Lal, A., White, R. M., "Silicon micromachined ultrasonic microcutter," IEEE Ultrasonic Symposium 1994, Nov 1-4, Camnes, France.

[2] Lal. A., White R.M., "Silicon microfabricated homs for power ultrasonics,", Transducers 95, July 24-27, Stockholm, Sweden.

[3] Lal, A., White, R. M., "Micromachined silicon ultrasonic pump," IEEE UIrasonics Symposium 1995, Nov. 7-10, Seattle, USA.

[4] Hunt, F.V., "Stress and strain limits on the attainable velocity in mechanical vibration," J. Acous. Soc. Am., vol. 32 No. 9, pp. 1123-1128, Sept. 1960.

[5] Ashby, M. F. Materials Selection In Mechanical Design, Pergamon, 1992.

[6] Petersen, K.E., "Silicon as a mechanical material," Proc. IEEE, vol. 70, no. 5, pp. 420-457, May 1982.

[7] C. J. Smithels, Ed., Metals Reference Handbook, London. England: Butterworths, 1976.

[8] Williams, A., Combustion of Liquid Fuel Sprays, Butterworth, 1990.

[9] Jackson, F. J., Nyborg, W. L., "Sonically-induced micro-streaming near a plane boundary. I. The sonic generator and the associated acoustic field," J. Acous. Soc. Am., vol. 32 No 10, pp 1243-1250, Oct. 1960.

[10] Jackson, F. J., "Sonically-induced micro-streaming near a plane boundary. II Acoustic streaming field," J. Acous. Soc. Am., vol. 32 No 11, pp 1387-1395, Nov. 1960.

[11] Singh, A., Mehregany, M., "Micromachined silicon fuel atomizers for Gas Turbine Engines," MEMS 95 proceedings, pp 473-478, San Diego, 1995.

[12] Bruetsch, R. I., Hamady, F. J., "Cold starting an alcohol-fueled engine with ultrasonic fuel atomization," EPA technical report EPA/AA/IDG/93-02a, 1993.

[13] Lierke, E. G., "Ultrasonic atomizer incorporating a self-acting liquid supply," Ultrasonics, October 1967, pp 214-218.

[14] Wang, W., Carter, R., "PZT ultrasonic pump," Ultrasonics, March 1986, pp $105-$ 106.

[15] Ericson, F., Schweitz, Jan-Ake, "Micromechanical fracture strength of silicon". J. Appl. Phys., 68(11), 1 December 1990, pp 5840-5844.

[16] Nelson, P. C., The Shape of Small Water Drops..., Dissertation, Univ. Calif. Berkeley, 1945.

[17] Lang, R. J., "Ultrasonic atomization of liquids," J. Acous. Soc. Am., vol. 34 No. 1, pp. 6-8, Sept. 1962.

\section{ACKNOWLEDGEMENTS}

This research was supported by the Berkeley Sensor \& Actuator Center (BSAC), an NSF/Industry/University Cooperative Research Center, funded by the National Science Foundation and a consortium of industrial corporations and government agencies. Research and fabrication of test structures was carried out in the Berkeley Micro-Fabrication Facility. 